\title{
OIL SEARCH AND OCCURRENCE IN GIPPSLAND, VICTORIA
}

$S^{\mathrm{II}}$ EDMUND TEALE, in a desire to clarify the position with regard to the occurrence of oil in Gippsland, has carried out a critical examination of published literature on the subject and has also paid a personal visit to the Lakes Entrance region in company with a geologist, a palæontologist and a consulting engineer. The report of his findings issued in July of this year shows that, in so far as the literature is concerned, this is in many ways incomplete and, moreover, embodies a wealth of conflicting opinions. For example, the Oil Advisory Committee's report of February 1937 reflects a cautious but optimistic view of oil possibilities in the Lakes Entrance area, while another report issued by the same authority and only a year later takes a definitely pessimistic outlook of such possibilities. A third report issued by the Committee at the end of 1938 was as constructive as the preceding one had been destructive.

Mr. E. A. Kodyen's report, written in 1939, considered the possibility of repressuring the Lakes Entrance field, but met with little support and definite opposition from Dr. A. Wade. Mr. F. Chapman advanced the view that there is a considerable thickness of "granite wash" below the glauconite or oil horizon, but this was not accepted by the Mines Department, which contends that the glauconite rests on or near bedrock. In spite of the importance of this point, reluctance was shown to permit the Government drilling plant to be used to decide the question. In 1937 Dr. Arthur Tieje visited the field and afterwards urged that a more complete and detailed study of underground structure should be made; but the investigation is still far from complete.

Sir Edmund Teale in his report maintains that incontrovertible data are still insufficient to permit accurate estimates to be made of proved resources. Moreover, investigations are not far enough advanced for any recommendations to be made as to the best method for recovery of the oil and the percentage which should be recovered. Nevertheless, results of carefully recorded tests carried out by the Austral Oil Company indicate that the area, if exploited, might be comparable with other low-pressure production fields in different parts of the world. Admittedly the oil is not petroliferous, but it yields three useful products, all of which have at present to be imported. These are bitumen, heavy oil and lubricating oil. In view of the usefulness of these products per se, it would not be necessary to consider the installation of cracking plants for the production of petrol. A disadvantage of the field is that it is definitely a low-pressure area where ordinary pumping methods are of little use. Some form of pressuring would be necessary and before embarking on any such scheme, expert advice would have to be procured.

During his inspection of the field, Sir Edmund visited Holland's Landing, near the western shore of Lake Victoria, where there is a modern plant in operation capable of attempting to penetrate the Tertiary deposits, which there attain a thickness of some 3,600 ft. In addition, sites were visited where scout drilling was in operation and also where boreholes had been completed and cores preserved for inspection. For the most part, however, there was evidence of much haphazard and unprofitable drilling carried out by private enterprise. Reliable records had not been kept until recently, when the Austral Oil Company undertook to make a series of regular tests from selected boreholes over a considerable period of time.

Sir Edmund's general impressions of his visit are summarized at the end of his report. Evidence of proved and potential oil in the Lakes Entrance area, in his opinion, warrants installation of approved methods to attempt recovery on a commercial scale. To this end the best technical advice procurable should be obtained. More geological information is required regarding the glauconite zone, the nature and thickness of underlying formations and the floor upon which they rest. Tertiary formations outside the Lakes Entrance area require special and more adequate exploration than is at present the case. Geophysical methods would facilitate this work.

Finally, in view of the present demand for oil of all kinds, Sir Edmund maintains that the undertaking should enlist the support of the Government and of private enterprise. Moreover, there is an urgency in the matter which calls for the immediate speeding-up of activities in this direction.

\section{ORIGIN OF THE EGYPTIAN CALENDAR}

\begin{abstract}
THE calendar of the ancient Egyptians was one of the earliest experiments in calendar making, and it was one of the most enduring. It was still in use at the beginning of the Christian era much as it had been in the Pyramid age three thousand years before, having had an uninterrupted existence throughout more than half of man's recorded existence. Many theories, all differing fundamentally, have been put forward as to its origin. These have been reviewed recently by $\mathrm{H}$. E. Winlock ("The Origin of the Ancient Egyptian Calendar", Proc. American Philo-
\end{abstract}

sophical Soc., 83, No. 3 ; 1940), introducing a further suggestion as to the natural phenomena which first marked the changing seasons for the ancient Egyptians and came to be the foundation of their calendrical system.

The approach to the problem has usually started with a statement by Censorinus in A.D. 238 that the Egyptian New Year Day in A.D. 139 fell on July 21 when the bright star Sothis (Sirius), after having been invisible for a season, made its annual reappearance in the eastern sky just before sunrise. Since the 